\title{
$\begin{array}{lllllllll}\mathrm{I} & \mathrm{N} & \mathrm{S} & \mathrm{T} & \mathrm{I} & \mathrm{T} & \mathrm{U} & \mathrm{T} & \mathrm{E}\end{array}$
}

\section{Household Reports of Energy Assistance Receipt Increased 48 Percent During Recession Proposed Cuts Threaten Vulnerable Families}

JESSICA A. BEAN

$\mathrm{P}$ resident Obama's 2012 budget proposes cutting $\$ 2.5$ billion from the $\$ 5.1$ billion energy assistance fund for low-income families at a time when families are struggling with higher energy costs amid a difficult economy. This brief documents energy assistance use among American households and finds both untapped need and a growing demand for help.

\section{The Low-Income Home Energy Assistance Program}

The federal Low-Income Home Energy Assistance Program (LIHEAP) assists vulnerable families in paying their home heating and cooling bills. Low-income households (defined as those with incomes less than 150 percent of the federal poverty threshold $)^{1}$ may apply for funds for heating or cooling expenses, crisis intervention to prevent energy-related emergencies such as utility shutoffs, or weatherization and energy-related home repairs. ${ }^{2}$ The Department of Health and Human Services allocates funds to state agencies through a needs-based formula, ${ }^{3}$ who may then grant those funds to community and nonprofit agencies to help eligible applicants locally. ${ }^{4}$ Within the federal guidelines, states have some flexibility to set lower eligibility ceilings and may choose to include fewer households than federal guidelines would, in order to better target the neediest households. ${ }^{5} \mathrm{~A}$ particular focus of the LIHEAP program is to serve households with members under age 5 , over age 60 , or those with a disability. However, long waiting lists and millions of eligible families left without assistance are common problems, as most states simply distribute funds on a first-come, first-served basis.?

\section{Key Findings}

- Between 2007 and 2010, 48 percent more households reported receiving winter energy assistance.

- A significantly higher percentage of households in the severe winter regions of the Northeast and Midwest receive assistance than in the warmer regions of the South and West.

- Households headed by a single parent more often report reliance on energy assistance, particularly in rural areas where rates of receipt are greater than 20 percent.

This brief uses data from the 2010 Current Population Survey's (CPS) Annual Social and Economic Supplement (ASEC) ${ }^{8}$ to explore winter energy assistance by region, place type, poverty status, and household composition. In addition, data from the Department of Health and Human Services (DHHS) are used to supplement the ASEC data, providing estimates of the number of households receiving assistance. These data are used in lieu of ASEC data, as ASEC data are known to underreport receipt of social service programs, due to the self-reported nature of the survey. ${ }^{9}$ However, underreporting is not expected to vary by the characteristics explored here; therefore ASEC data are used to examine trends in receipt across demographics. 


\section{Demand for Assistance Grew Rapidly}

The need for assistance grew rapidly in the span of three years. Nationwide, from the winter of 2006/2007 to the winter of 2009/2010, there was a 48 percent increase in households reporting energy assistance receipt. ${ }^{10} \mathrm{This}$ remarkable growth during the recession stands in stark contract to the less than 1 percent increase in households receiving assistance from the winter of 2003/2004 to the winter of 2006/2007 (a period of relative prosperity). ${ }^{11}$ DHHS data estimate that nearly 7.7 million households received energy assistance in fiscal year $2009,{ }^{12}$ though many more households were eligible. In fact, DHHS data show that only 16 percent of income eligible households received energy assistance in fiscal year $2008,{ }^{13}$ the most recent date for which data are available. However, there are no data indicating how many eligible households were turned away due to high demand, meaning it is unclear if the low participation is due to limited resources or low demand. Most likely, it is the former, as other sources suggest that LIHEAP funds are inadequate for meeting need. States often run out of funds during the heating season,,$^{14}$ and are sometimes forced to close their waiting lists while waiting for funds to be renewed. ${ }^{15}$

\section{Highest Rates of Assistance Are in Rural Areas}

The highest rates of reported energy assistance are in rural areas, particularly in the rural Northeast and Midwest (see Figure 1) ${ }^{16}$ For one, rural residents are more likely to live in less-energy-efficient homes, such as mobile homes or singlefamily homes (versus large apartment buildings). ${ }^{17}$ In addition, the harsh winters of the Northeast and Midwest and the high price of heating oil drive up energy costs, meaning that these cost-burdened households may be given additional consideration by federal and state funding formulas. ${ }^{18}$ Extreme weather results in both more funds for distribution and more applicants requesting those funds, resulting in higher receipt numbers. ${ }^{19}$ Despite the higher percentage of rural households reporting assistance, it should be noted that the population is more heavily concentrated in urban and suburban areas. That is, though a higher percentage of households in rural areas report assistance, the total number of energy assistance recipients is split approximately into thirds by rural, suburban, and central city residence (32, 36, and 32 percent, respectively). Similarly, while the percentage of recipients is highest in the Northeast and Midwest, still nearly one in four households receiving assistance is in the South (23 percent) and nearly one in five is in the West (18 percent).
Figure 1. Receipt of Energy Assistance Among Low Income Households, By Region ANd Place*

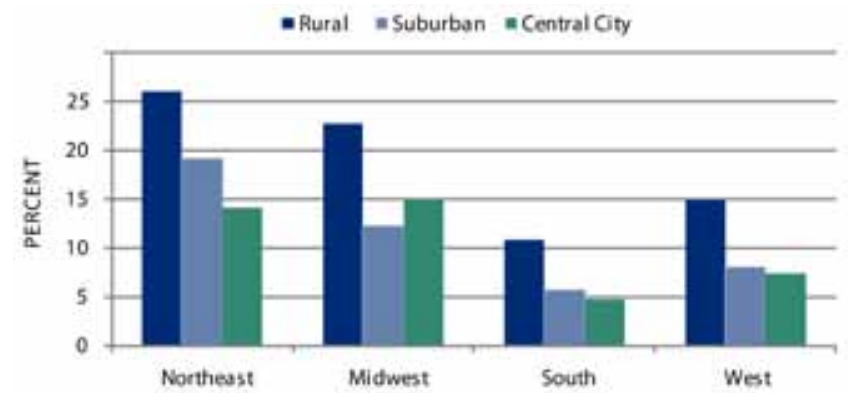

${ }^{*}$ Receipt in the Northeast and Midwest is significantly higher than that in the South or West. Note: All data are weighted.

The average reported benefit amount also varies by region of the country, largely because of the influence of fuel type and weather conditions on fuel expenditures. As Figure 2 shows, the lowest average benefit is reported in the West South Central region, at an average of $\$ 249$ during the winter of 2009-2010. New Englanders received the highest average benefit, at $\$ 747$ last winter. However, this assistance likely covers only a fraction of total home heating costs. About seven in ten New England homes use heating oil, the most expensive home heating option, and may pay up to $\$ 3,000$ in heating costs each winter..$^{20}$ Thus, a New England family with an average energy assistance benefit could still face more than $\$ 2,200$ in heating costs, or be left unable to adequately heat their home.

Figure 2. Energy Assistance By Region

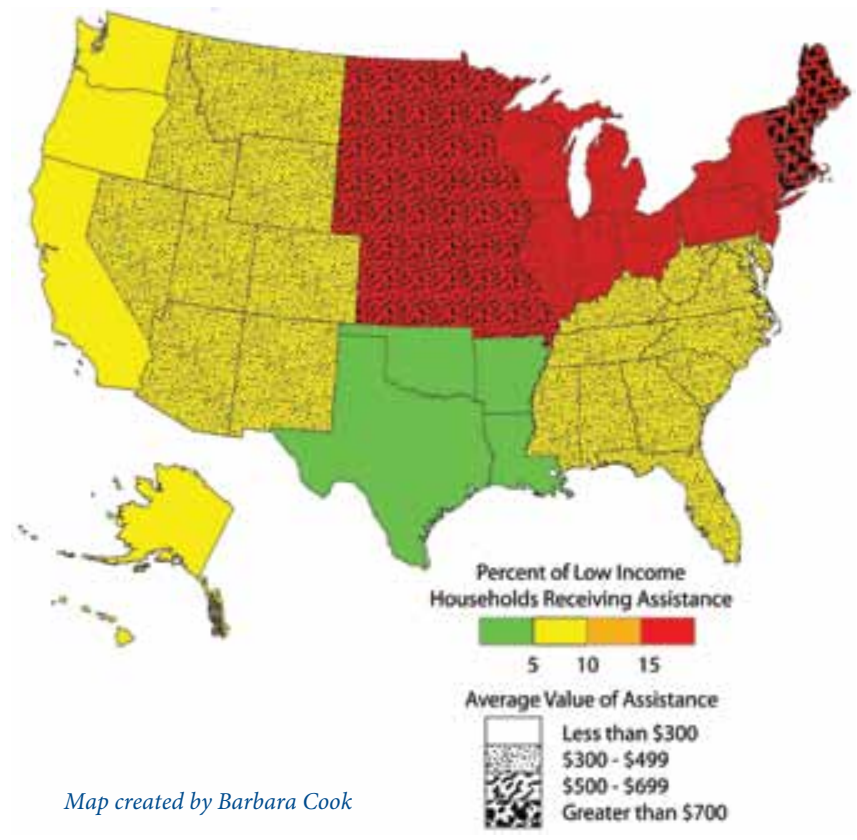




\section{Family Differences}

Households headed by a single parent are more likely to report receiving energy assistance than are married-parent households, with more than 20 percent of rural single parents reporting receipt, compared with 13 percent of marriedparent households. Low-income single parents in rural areas are significantly more likely to report energy assistance than their suburban or central city counterparts, and rates of receipt in suburban and central city areas are comparable (see Figure 3). Although households with a member under age 18 were more likely to receive energy assistance than other low-income households, those with a child under age 6 were not more likely to report receiving assistance-despite LIHEAP's goals of focusing on families with young children. Similarly, households with a member over age 60 were no more likely to report receiving assistance than other lowincome households. However, low-income households with a disabled member were much more likely to report receiving assistance.

Figure 3. Receipt of Energy Assistance Among Low INCOME PARENTs*

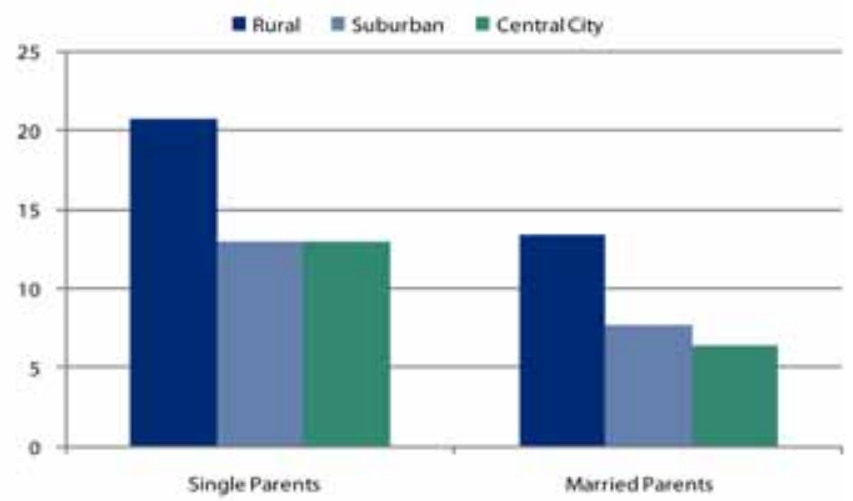

${ }^{*}$ Receipt in rural areas is significantly higher $(p<0.001)$ than in suburban or central city areas for both family types. Suburban and central city rates are statistically indistinguishable. Rates among single parents are significantly higher than among married parents. Note: All data are weighted.

\section{Funding Shortfalls and Narrow Eligibility Determinations Leave Too Many Out in the Cold}

As the above analyses show, LIHEAP is an important program for millions of households, though there are likely millions more who could benefit from assistance. In particular, households with very young or elderly members should be better targeted, as only 12 percent and 11 percent of these eligible households receive assistance, respectively. ${ }^{21}$ Congress has encouraged administrators to consider the energy burden of households (defined as the households' energy expenditures divided by their household income) and the energy needs of households (defined as the energy burden plus the unique needs of vulnerable family members, such as the elderly, children, and people with disabilities) in determining LIHEAP eligibility. ${ }^{22}$ However, only twenty four states consider a household's energy burden, and only seventeen states consider energy need in their current LIHEAP allocation formulas. ${ }^{23}$ By not considering these important factors and setting strict income guidelines, many needy households are currently ineligible under their state rules. It appears many more households are struggling to afford energy costs than are able to access assistance owing both to narrow determinations of eligibility and an overall lack of funding.

President Obamas 2012 budget proposes cutting $\$ 2.5$ billion from the $\$ 5.1$ billion energy assistance fund. ${ }^{24}$ Proposed cuts would have a concrete and immediate impact on families, particularly those in rural areas and in harsh winter climates. A survey from the National Energy Assistance Directors' Association (NEADA) found that unaffordable energy bills result in families "regularly taking funds from food, medical [expenses], and other basic needs in order to make energy payments and avoid... disconnection." ${ }^{25}$ More than 30 percent of respondents to that survey reported underpaying or missing a mortgage payment, and one-third of respondents had relied on their kitchen stove or oven to provide heat in the last year, both because of unaffordable energy bills. ${ }^{26}$ NEADA projects that the number of eligible applications will increase in eighteen states by 10 percent or more during 2011 (including increases of over 50 percent in two states). ${ }^{27}$ The findings together show that LIHEAP remains underfunded even as need grows in the midst of a serious recession. Budget cuts will only make matters worse.

\section{Data}

This brief uses data from the U.S. Census Bureau's Current Population Survey's (CPS) Annual Social and Economic Supplement conducted in February-April 2004, 2007, and 2010. Data included here thus apply to the winter of 2009/2010 (and the winters of 2003/2004 and 2006/2007 where referenced). The CPS provides a nationally representative sample of approximately 50,000 households and the individuals in those households, and collects demographic, economic, and employment information, as well as participation in select government assistance programs. The analyses here are limited to responses from householders only. Comparisons presented in the text are statistically significant at the 0.05 level. 


\section{E N D N O T E S}

1. LIHEAP eligibility is determined in multiple ways: income eligibility (households reporting income less than $150 \%$ of the federal poverty line or households reporting income less than $60 \%$ of the state median income, whichever is higher), and categorical eligibility (households reporting receipt of Temporary Aid for Needy Families, Supplemental Security Income, food stamps, or some veterans' benefits). As eligibility requirements vary so greatly state by state and because the availability of state-by-state data is limited, the calculations here are restricted to the federal criteria of income less than $150 \%$ of the federal poverty line. Therefore, while results here likely underestimate the number of households that are eligible, the focus here is strictly on low income and poor households.

2. "Program Benefits." 2005. ACF Questions and Answers Support. Administration for Children and Families. Washington, DC: U.S. Department of Health and Human Services.

3. The allocation formula is based on 75 variables, including fuel type and usage, fuel costs, and climate conditions. See http://www.acf.hhs.gov/programs/ocs/liheap/funding/fund. html for more information.

4. "Program Benefits." 2005. ACF Questions and Answers Support. Administration for Children and Families. Washington, DC: U.S. Department of Health and Human Services.

5. "Putting LIHEAP into Context: Addressing Americans Unmet Need for Low-Income Energy Assistance." 2007. Low-Income Best Practices Workshop, January 30-February 1, 2007. Washington, DC: Edison Electric Institute.

6. "Program Statistics." 2010. Performance Measure, Low Income Home Energy Assistance Program. Washington, DC: Administration for Children and Families, U.S. Department of Health and Human Services.

7. Ibid.

8. The CPS questionnaire asks respondents "Since October 1 , [2009] has this household received energy assistance from the federal, state, or local government?" As LIHEAP is the largest source of federal, state, and local energy assistance funds, this paper uses the terms "LIHEAP" and "energy assistance" interchangeably.

9. In addition to the known risk of intentional underreporting, ASEC data may underestimate receipt for several reasons: the CPs does not track movers, who may be more likely to use LIHEAP; estimates are limited to reports from householders only, who may be unaware of receipt by other household members; and estimates are limited to those reporting receipt between October and the survey month (February, March, or April). While these limitations might bias estimates slightly, there is no reason to believe that overall trends would vary drastically from those in the population.

10. Carsey Institute analysis of ASEC data; not shown.
11. Carsey Institute analysis of ASEC data; not shown.

12. See "Table 1: LIHEAP Winter Heating Households Served FY09 \& FY 10 Projec[t]ed." 2010. February 22, Press Release. Washington, DC: National Energy Assistance Directors' Association. Available at http://www.neada.org/ communitcations/press/2010-02-22Table\%201-LIHEAP10ProjServed.pdf.

13. See "LIHEAP Home Energy Notebook for Fiscal Year 2008.” 2010. Washington, DC: Department of Health and Human Services, Administration for Children and Families, Office of Community Services, Division of Energy Assistance.

14. "Putting LIHEAP into Context: Addressing Americans Unmet Need for Low-Income Energy Assistance." 2007. Low-Income Best Practices Workshop, January 30-February 1, 2007. Washington, DC: Edison Electric Institute.

15. See, for example, "Where to Apply." 2011. Washington State Department of Commerce, at http://www.liheapwa.org/ and "Program Waiting List Continues to Remain Closed." 2011. Lane County Oregon County Website, at http://www. lanecounty.org.

16. Rates of receipt among eligible households are significantly lower in suburban and central city areas, at 10 percent and 9 percent, respectively (compared to 16 percent in rural areas). Carsey Institute analysis of ASEC data; not shown.

17. See "Table HC2.1: Housing Characteristics by Type of Housing Unit.” 2005. Residential Energy Consumption Survey. Washington, DC: Energy Information Assistance, Department of Energy.

18. Perl, Libby. 2010. “The LIHEAP Formula: Legislative History and Current Law." CRS Report for Congress No. 7-7500. Washington, DC: Congressional Research Service.

19. Ibid.

20. "New England Household Electricity Report." 2005. Regional Energy Profile. Washington, DC: Energy Information Administration, Department of Energy. For heating oil costs, see Stone, Chad, Arloc Sherman, and Hannah Shaw. 2011. "Administration's Rationale for Severe Cut in Low-Income Home Energy Assistance is Weak." February 18 Report. Washington, DC: Center on Budget and Policy Priorities. The \$3,000 figure comes from "U.S Heating Oil and Propane Prices, 2/14/2011" 2011. Heating Oil and Propane Update. Washington, DC: U.S. Energy Information Administration, and Gavin, Robert. 2007. "Heating Oil Users Face Costly Winter." The Boston Globe, November 1. Retrieved February 18.

21. Carsey Institute analysis of ASEC data; not shown.

22. "LIHEAP Heating Assistance: Criteria for Varying Benefits." 2010. LIHEAP Clearinghouse. Administration for Children and Families. Department of Health and Human Services.

23. Ibid. 
24. "Fiscal Year 2012: Terminations, Reductions, and Savings: Budget of the U.S. Government.” Washington, DC: Office of Management and Budget. Retrieved February 16, 2011 (http://www.whitehouse.gov/sites/default/files/omb/ budget/fy2012/assets/trs.pdf).

25. "Putting LIHEAP into Context: Addressing Americans Unmet Need for Low-Income Energy Assistance.” 2007. Low-Income Best Practices Workshop, January 30-February 1, 2007. Washington, DC: Edison Electric Institute.

26. Choate, Jo-Ann and Mark Wolfe. 2010. “2009 National Energy Assistance Survey.” Washington, DC: National Energy Assistance Directors' Association.

27. States with expected increases of 10 percent or more include: Colorado, Hawaii, Kansas, Louisiana, Maryland, Massachusetts, Mississippi, New York, North Carolina, Rhode Island, South Carolina, South Dakota, Tennessee, Texas, Wisconsin, and Wyoming. States with increases of 50 percent or more include Florida (50 percent) and Vermont (64 percent). See "Applications for Energy Assistance Again Reach Record Levels." 2011. Press Release, February 9. Washington, DC: National Energy Assistance Directors' Association.

\section{ABOUT THE AUTHOR}

Jessica A. Bean is a vulnerable families research associate at the Carsey Institute (Jessica.bean@unh.edu).

\section{A C K N O W L E D G M E N T S}

The author thanks Beth Mattingly, Mil Duncan, Curt Grimm, Amy Sterndale, Andrew Schaefer, and Laurel Lloyd Earnshaw at the Carsey Institute; Arloc Sherman and Hannah Shaw at the Center on Budget and Policy Priorities; and Barbara Ray at Hired Pen for their thoughtful comments and suggestions. Special thanks to Barbara Cook at the Carsey Institute for creating the map. 


\section{$\triangle$ UNIVERSITY of NEW HAMPSHIRE}

\section{CARSEY}

Building knowledge for families and communities

The Carsey Institute conducts policy research on vulnerable children, youth, and families and on sustainable community development. We give policy makers and practitioners timely, independent resources to effect change in their communities.

This work was supported by the Annie E. Casey Foundation, the W. K. Kellogg Foundation, and an anonymous donor.

Huddleston Hall

73 Main Street

Durham, NH 03824

(603) $862-2821$

www.carseyinstitute.unh.edu 